\title{
5. Structure of a COBOL Program
}

A COBOL program is made up of four Divisions:

1. The IDENTIFICATION DIVISION.

This must contain the program's name - as follows:

PROGRAM-ID. name

2. The ENVIRONMENT DIVISION.

If the program uses peripheral devices (e.g. disk, tape, printer) - details will be shown here. Otherwise, this division will often be empty.

3. The DATA DIVISION.

This describes the memory space needed for data the program will use. It contains one or more SECTIONS; the most common are the FILE SECTION and the WORKING-STORAGE SECTION.

4. The PROCEDURE DIVISION.

This contains the actual program instructions. It may be split into Sections and Paragraphs (with names given by the programmer).

Example Program

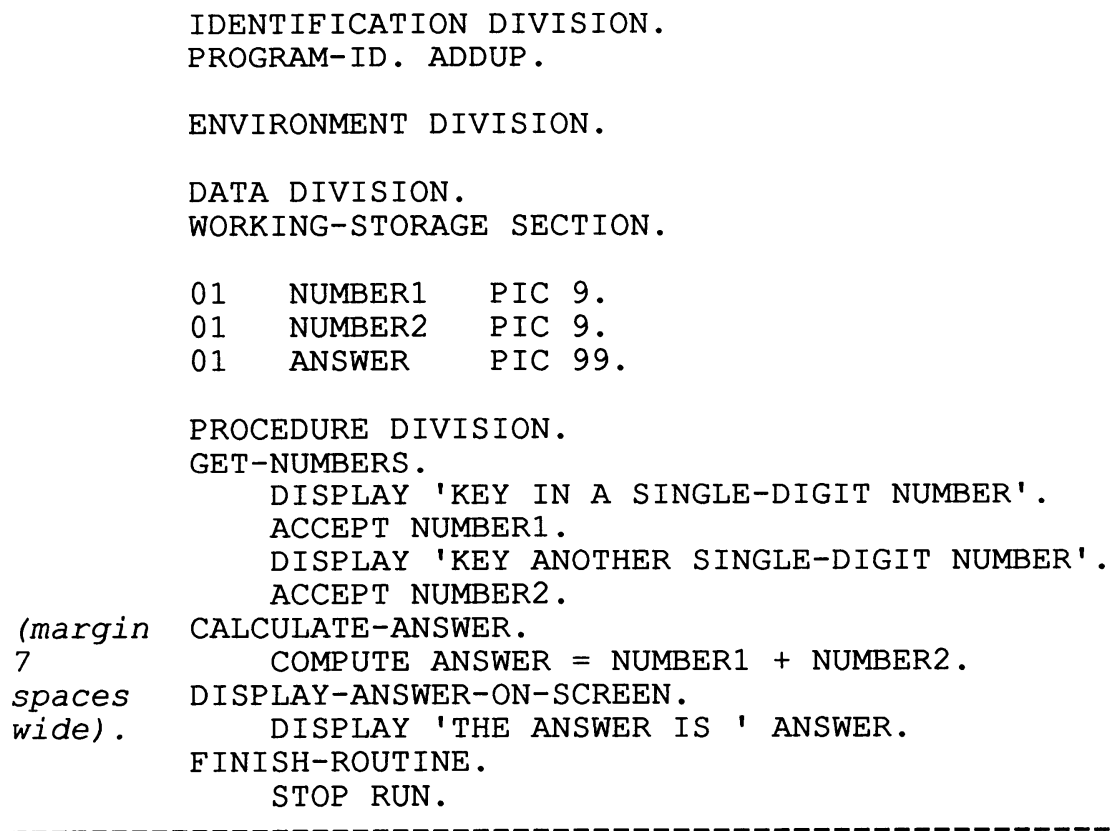

Try the example program on a computer - KEY IT IN EXACTLY AS SHOWN - taking special care over punctuation, indentation, spaces between words and after full-stops.

Exercise

Write programs

1. to ask for 4 single-digit numbers and print a total;

2. to ask for a number, double it and print the answer. 